\title{
Malabsorption in Infants with Congenital Heart Disease under Diuretic Treatment
}

\author{
NACHUM VAISMAN, TIRZAH LEIGH, HILLARY VOET, KLAAS WESTERTERP, \\ MATITIAU ABRAHAM, AND ROLAND DUCHAN
}

Pediatrics Department, Kaplan Hospital, Rehovot, Israel [N.V., M.A.]; Faculty of Agriculture, Rehovot, Israel [T.L., H.V.]; The Soreq Nuclear Research Center, Yavne, Israel [R.D.]; and Department of Human Biology, University of Limburg, Maastricht, The Netherlands [K.W.]

\section{ABSTRACT}

Intestinal absorption and its relationship to increased total body water was studied in seven infants with congenital heart disease receiving regular diuretics due to congestive heart failure. All infants and six age-matched healthy controls were studied for a 3-d period during which time all food intake was recorded, stools were collected, and total body water content (TBW) and extracellular water were measured. All the anthropometric measurements were lower in the infants with congenital heart disease compared with healthy controls. Energy and fat excretion in the stools were significantly increased in the group of patients, but when expressed as a percentage of daily caloric intake or as a percentage of the specific intake (e.g. fat excretion/ fat intake $\times 100$ ), no statistical differences were found. TBW as a percentage of body weight was increased in our patients compared with our controls $(84.95 \pm 5.82 \%$ versus $68.65 \pm 4.60 \% ; p=0.01$ ) and so was extracellular water as a percentage of predicted $(200.0 \pm 18.6 \%$ versus $100.9 \pm$

Failure to thrive is commonly observed in infants with CHD $(1,2)$. Different causes have been suggested to play a role in this process, among which are poor caloric intake, increased energy expenditure, and intestinal malabsorption due to intestinal congestion (3). Some patients with $\mathrm{CHD}$ fail to gain weight or gain weight insufficiently, in spite of increased energy intake. The question then arises whether one should further increase their energy intake or should look for other causes involved in this process, such as increased malabsorption due to increased caloric content or malabsorption due to congested intestinal wall.

The present study was designed to study intestinal absorption in infants with CHD who are on diuretic treatment due to previous status of congestive heart failure and to try to correlate intestinal malabsorption with different degrees of increased body water content and different caloric intakes. Increased water content,

Received October 21, 1993; accepted April 21, 1994.

Correspondence: Nachum Vaisman, M.D., Kaplan Hospital, Pediatrics Department B, Rehovot 76100, Israel.
$7.2 \% ; p=0.001)$. A positive correlation was found between energy and fat excretion as a percentage of the intake and TBW as a percentage of predicted; energy and fat malabsorption did not exceed $8 \%$ in the patients with the highest body water content ( $120 \%$ of predicted). It is concluded that malabsorption is not a significant factor in failure to thrive of patients with congenital heart disease who are receiving regular diuretics. Based on the significant negative correlation between excess body water and fat and calorie absorption, however, it is suggested to monitor TBW in patients who fail to gain weight. (Pediatr Res 36: 545-549, 1994)
Abbreviations
CHD, congenital heart disease TBW, total body water content ECW, extracellular water

reflected by increased TBW and ECW in patients with significant intestinal malabsorption, may indicate a possible relationship between these parameters.

\section{METHODS}

The study population consisted of seven infants with CHD and six age-matched normal controls. Patients' characteristics are given in Table 1. Each patient was evaluated in the past by a pediatric cardiologist (M.A.) for the degree of his or her congestive heart failure. Clinical diagnosis of heart failure was based on clinical parameters such as tachypnea, hepatomegaly, and enlarged heart silhouette on radiologic examination. Respiratory causes of the aforementioned were excluded. Most of the patients who were catheterized had a low cardiac index, based on Fick equations. All our patients were receiving regular diuretics and digoxin treatment and were clinically stable during the study period. All our controls were healthy, normal infants with no CHD who were recruited from the hospital personnel. 
Table 1. Patients' characteristics*

\begin{tabular}{|c|c|c|c|c|c|c|c|c|}
\hline No. & Sex & $\begin{array}{l}\text { Age } \\
(\mathrm{mo})\end{array}$ & $\begin{array}{l}\text { Weight } \\
(\mathrm{kg})\end{array}$ & $\begin{array}{c}\text { Height } \\
(\mathrm{cm})\end{array}$ & WFH\% & $\begin{array}{l}\text { HDcirc } \\
(\mathrm{cm})\end{array}$ & Diagnosis & $\mathrm{CHF}$ \\
\hline \multicolumn{9}{|l|}{ Patients } \\
\hline 1 & M & 3 & 5.05 & 58 & 93.52 & 38 & $\begin{array}{l}\text { DORV, mitral atresia } \\
\text { hypoplastic LV }\end{array}$ & Mild \\
\hline 2 & $\mathrm{~F}$ & 5.5 & 6.6 & 68 & 85.71 & 42 & Large PDA & Mild \\
\hline 3 & $\mathbf{M}$ & 5 & 4.8 & 64 & 69.57 & 39 & AV-canal, Down's & Moderate \\
\hline 4 & M & 3.5 & 3.75 & 55.5 & 75.00 & 38.5 & VSD, ASD, PDA & Moderate \\
\hline 5 & M & 2.5 & 3.5 & 55 & 77.17 & 38 & VSD, COA & Moderate \\
\hline 6 & $\mathbf{M}$ & 4 & 4.5 & 59 & 78.95 & 40.5 & DORV, VSD, TGA & Severe-moderate \\
\hline 7 & $\mathrm{~F}$ & 1.5 & 3.255 & 52 & 83.46 & 32 & AV-canal, Down's & Severe \\
\hline Mean & & 3.57 & 4.50 & 58.80 & 80.48 & 38.29 & & \\
\hline $\pm 1 \mathrm{SD}$ & & \pm 1.40 & \pm 1.14 & \pm 5.54 & \pm 7.84 & \pm 3.13 & & \\
\hline \multicolumn{9}{|l|}{ Controls } \\
\hline Mean & & 4.25 & 6.45 & 64.0 & 94.85 & 42.42 & & \\
\hline $\pm 1 \mathrm{SD}$ & & 1.84 & 0.93 & 2.45 & 4.96 & 2.62 & & \\
\hline $\begin{array}{l}p \text { value between } \\
\text { groups }\end{array}$ & & NS & 0.007 & NS & 0.003 & 0.03 & & \\
\hline
\end{tabular}

* WFH\%, percentage of ideal weight for height; HDcirc, head circumference; CHF, chronic heart failure; M, male; F, female; DORV, double-outlet right ventricle; LV, left ventricle; AV-canal, atrioventricular canal; VSD, ventricular septal defect; ASD, atrial septal defect; PDA, patent ductus arteriosus; COA, coarction of the aorta; TGA, transposition of the great vessels.

The study was approved by the Human Subject Review Committee, the Kaplan Hospital, Rehovot, and informed consent was obtained from the parents before the study.

Study design. All infants were studied for a 3-d balance period during which time all food intake was recorded, stools were collected, and TBW was measured. Patients were admitted to the pediatric ward $24 \mathrm{~h}$ before commencing the study. Patients stayed on their regular diet, and no attempt was made to increase food intake during the study time. None of the infants were fully tube fed. Weight, height, and head circumference were recorded, and weight as a percentage of ideal weight for height was calculated (4).

Food intake. Food intake was recorded by weighing bottles before and after feedings using electronic scales (Keter, Rehovot, Israel) to $0.2 \mathrm{~g}$ accuracy. Losses by emesis were estimated by weighing and were subtracted from the total intake. The caloric content of the infant formula was determined by bomb calorimeter, nitrogen content by microKjeldhal technique, and fat content gravimetrically.

Stool collection. Infants were placed on a metabolic frame from which stools were collected. The beginning and end of each collection period were marked by administering active charcoal to the morning feed on $\mathrm{d} 1$ and 4 . Stools were weighed at the end of each collection period and stored at $-20^{\circ} \mathrm{C}$ for further analysis. A sample was taken for $\alpha_{1}$-antitrypsin analysis (5).

Metabolic balance. Energy content of the formulas and stools was analyzed by using a bomb calorimeter (Parr, Adiabatic Calorimetry, Moline, IL). Nitrogen was analyzed using micro-Kjeldahl digestion and an automated phenate-hypochlorite method (6), and fat was determined gravimetrically after acid hydrolysis (7).

Energy absorption was calculated as the difference between daily intake and daily output (stools) and expressed as a percentage of energy intake. Fat and protein absorptions were expressed as a percentage of total en- ergy intake as well as a percentage of the specific intake (e.g. protein excretion/protein intake $\times 100)$.

TBW and ECW measurements. TBW was determined by deuterium oxide $(0.1 \mathrm{~g} / \mathrm{kg}$ body weight) $99.8 \%$ enrichment (Cambridge Isotope Laboratories, Woburn, MA). The isotope was administered nasogastrically on the second day of the experiment at least $2 \mathrm{~h}$ after the last meal. The next meal was postponed until the end of the study. Heparinized blood samples were drawn before isotope administration and $3 \mathrm{~h}$ later.

TBW was calculated from the isotope dilution ${ }^{2} \mathrm{H} / \mathrm{H}$ in each plasma sample (8). Deuterium concentration in background and 3-h blood samples was determined with an Aqua-Sira mass spectrometer (VG Isogas Ltd., Middlewich, UK). ECW was calculated from the corrected bromide space $(\mathrm{NaBr} 3 \%, 1 \mathrm{~mL} / \mathrm{kg})$, as previously described (9). Bromide concentrations were analyzed by neutron activation. This procedure measures the concentration of bromide $\left({ }^{82} \mathrm{Br}\right)$ produced by irradiating the naturally occurring stable isotope of bromide, ${ }^{81} \mathrm{Br}$, with thermal neutrons using the Slowpoke reactor (Israel Research Reactor). The half-life of ${ }^{82} \mathrm{Br}$ is $35.4 \mathrm{~h}$. Samples were irradiated at a flux of $5 \times 10^{12}$ neutrons $/ \mathrm{cm}^{2} / \mathrm{s}$. The decaying of ${ }^{82} \mathrm{Br}$ gamma rays were counted by using a $100-\mathrm{mL} \mathrm{Ge}(\mathrm{Li})$ detector (Seforad, Migdal Haemek, Israel) coupled with a Tennelec TC 242 amplifier (Oxford Instruments, Inc., Oak Ridge, TN) and a multichannel analyzer (Ortec CE A63, Oxford Instruments, Inc.). Gamma ray intensities were calculated by averaging the regions of interest at the positions of 544 and $777 \mathrm{keV}$ gamma ray peaks. The intensities were then coupled with the appropriate average specific activity obtained by analyzing standard samples of bromide in the plasma. Corrected bromide space (CBS) was calculated using the following formula: $\mathrm{CBS}=\mathrm{Br}$ dose $/ \mathrm{Br}$ plasma $\times 0.90 \times$ $0.95 \times 0.94$, in which 0.90 is the correction for nonextra- 
cellular distribution, 0.95 is the Donnan equilibrium factor, and 0.94 is the correction of water in the plasma, which is $0.94 \%$.

The predicted values for TBW and ECW were derived from Cheek's equations (10) and expressed as TBW as a percentage of predicted and ECW as a percentage of predicted.

Statistics. The two groups were compared by the unpaired $t$ test for the different parameters. Pearson correlation coefficients were used to correlate the different parameters and partial correlation coefficients between two parameters while keeping a third relevant parameter constant. Results were expressed as mean \pm 1 SD.

\section{RESULTS}

All the anthropometric measurements were lower in the group of infants with CHD compared with our normal controls (Table 1).

No significant statistical difference was found in the energy, fat, or protein intakes of our patients compared with our normal control group, expressed per daily intake (Table 2).

Energy and fat excretion in the stools was significantly increased, in absolute numbers, in our group of patients compared with our normal controls (Table 2). However, when expressed as a percentage of daily caloric intake or as a percentage of the specific intake (e.g. fat excretion/ fat intake $\times 100$ ), no statistical differences were found in the excretion of the different substrates (Table 3). $\alpha_{1}$ Antitrypsin excretion was not different in our patients compared with our normal controls.

TBW was increased in our patients compared with our normal controls but did not reach significance as a percentage of the predicted values $(110.4 \pm 8.5 \%$ versus 97.1 $\pm 3.98 \%, p=0.08$ ) (Table 3). A significant difference was found in ECW as a percentage of predicted (200.0 \pm $18.6 \%$ versus $100.9 \pm 7.2 \%, p<0.001)$.

Table 2. Total enengy, fat, and protein intake and excretion (mean $\pm 1 S D)$

\begin{tabular}{lccc}
\hline & CHD group & Controls & $\begin{array}{c}\text { Significance } \\
\text { of difference }\end{array}$ \\
\hline Total intake* & & & \\
$\quad$ Energy (kcal) & $155.6 \pm 72.5$ & $105.5 \pm 38.3$ & NS \\
$\quad$ Protein (g) & $2.3 \pm 0.43$ & $2.6 \pm 0.86$ & NS \\
$\quad$ Fat (g) & $6.7 \pm 2.6$ & $4.6 \pm 2.1$ & NS \\
Total excretion* & & & \\
$\quad$ Energy (kcal) & $5.2 \pm 1.3$ & $3.1 \pm 1.1$ & 0.01 \\
$\quad$ Protein (g) & $0.19 \pm 0.08$ & $0.15 \pm 0.06$ & NS \\
Fat (g) & $0.25 \pm 0.06$ & $0.14 \pm 0.06$ & 0.01 \\
As a \% of caloric intake & & & \\
kcal/kcal\% & $3.90 \pm 1.78$ & $2.95 \pm 0.80$ & NS \\
Fat/kcal\% & $1.79 \pm 0.87$ & $1.22 \pm 0.32$ & NS \\
$\quad$ Protein/kcal\% & $0.64 \pm 0.45$ & $0.59 \pm 0.25$ & NS \\
As a \% of specific intake & & & \\
$\quad$ Fat/fat\% & $4.59 \pm 2.36$ & $3.36 \pm 1.23$ & NS \\
Protein/protein\% & $8.68 \pm 4.23$ & $5.90 \pm 2.09$ & NS \\
$\alpha_{1}$-Antitrypsin & $1.15 \pm 1.0$ & $0.71 \pm 0.22$ & NS \\
(mg/g feces) & & & \\
\hline
\end{tabular}

* Units are per kg body weight per day.
Table 3. $T B W, T B W$ as a percentage of body weight (TBW\%), $T B W$ as a percentage of predicted (TBWPP\%),ECW, and $E C W$ as a percentage of predicted (ECWPP\%) (mean $\pm 1 S D)$

\begin{tabular}{lccc}
$\begin{array}{c}\text { Water } \\
\text { compartment }\end{array}$ & CHD group & Controls & $\begin{array}{c}\text { Significance } \\
\text { of difference }\end{array}$ \\
\hline TBW (L) & $3.7 \pm 0.9$ & $4.9 \pm 0.2$ & $p=0.01$ \\
TBW\% & $84.95 \pm 5.82$ & $68.65 \pm 4.60$ & $p=0.01$ \\
TBWPP\% & $110.41 \pm 8.50$ & $97.05 \pm 3.98$ & $p=0.08$ \\
ECW (L) & $3.2 \pm 0.8$ & $2.2 \pm 0.4$ & $p=0.01$ \\
ECWPP\% & $200.0 \pm 18.6$ & $100.9 \pm 7.2$ & $p=0.001$ \\
\hline
\end{tabular}

When fat excretion as a percentage of fat intake and as a percentage of energy intake was examined versus TBW as a percentage of predicted, a positive correlation was found in our sick patients $[r=0.96(p=0.002)$ and $r=$ $0.82(p=0.04)$, respectively] (Fig. 1). Although this points to increased malabsorption when TBW is in excess of the predicted, in our sample the maximum fat excretion as a percentage of fat intake was not higher than $8 \%$ when TBW was $20 \%$ above the predicted value.

Table 4 demonstrates the correlations between our main parameters: energy and fat intake, energy and fat absorption, and TBW as a percentage of predicted. Negative correlations were found between energy and fat intake and the different measurements of malabsorption (Fig. 2). After correcting for the effect of TBW on these parameters, the partial correlations between total intake and energy excretion were $r=-0.33$ (NS) and $r=-0.42$ (NS) for total calorie and fat excretion, respectively. A positive correlation was found between excess water content and malabsorption. This association persisted even after correcting for a possible intake effect, and a partial correlation of $0.89(p=0.04)$ was observed. Excess water content was negatively correlated with energy and fat intake.

\section{DISCUSSION}

Our results indicate that infants with CHD receiving regular diuretics for congestive heart failure do not sig-

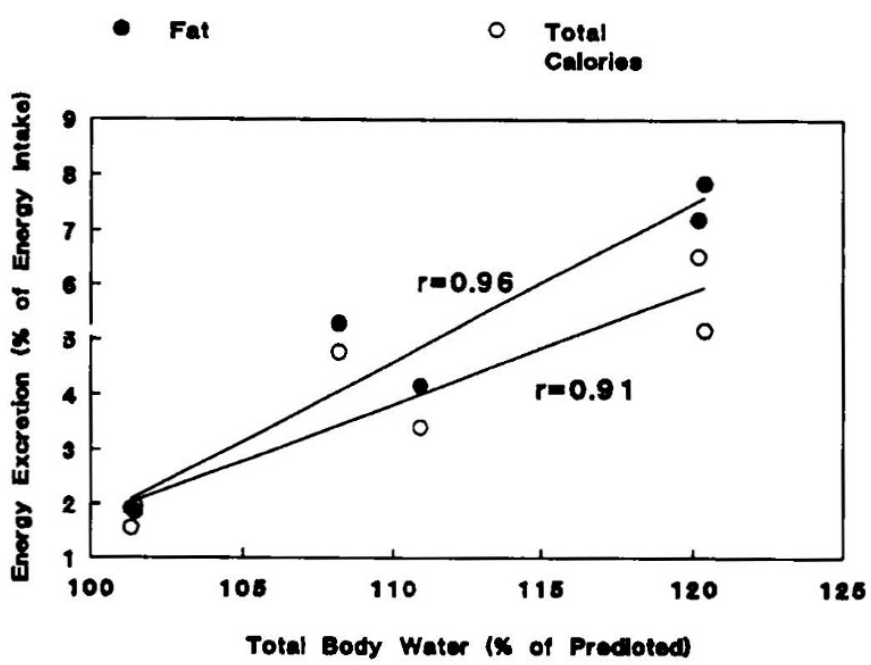

Figure 1. Fat and energy excretions as a percentage of energy intake, as a function of TBW percent of predicted. 
Table 4. Correlations between intake, excretion, and excess body water content

\begin{tabular}{lcc}
\hline & TBWPP* & $\begin{array}{c}\text { Energy } \\
\text { intake }\end{array}$ \\
\hline Energy intake & $r=0.81$ & \\
& $(p=0.05)$ & \\
Fat intake & $r=-0.99$ & $r=0.76$ \\
& $(p=0.0001)$ & $(p=0.05)$ \\
Energy excretion/energy intake & $r=0.91$ & $r=-0.80$ \\
& $(p=0.01)$ & $(p=0.03)$ \\
Fat excretion/fat intake & $r=0.96$ & $r=-0.79$ \\
& $(p=0.002)$ & $(p=0.04)$ \\
\hline
\end{tabular}

* TBWPP, TBW as a percentage of predicted.

nificantly malabsorb. The level of malabsorption is not unreasonable for these patients. A tendency toward fat malabsorption is seen when TBW is $20 \%$ higher than predicted, but even then malabsorption is not significant. In spite of the small sample size, the $95 \%$ confidence limits for total caloric excretion/caloric intake are $2.12 \%$ and $5.68 \%$, indicating, with $95 \%$ certainty, that mean caloric malabsorption for CHD patients receiving diuretics is at least $2.12 \%$ and at most $5.68 \%$. Fat excretion/fat intake values in the sample are all less than $8 \%$, even when TBW is $20 \%$ above predicted. In addition, the $95 \%$ confidence limits for the mean are $2.23 \%$ and $6.95 \%$, so that the highest feasible level for fat malabsorption is also not large enough to explain failure to thrive. Very few studies have dealt with intestinal malabsorption in patients with CHD and congestive heart failure. Our results are in accordance with previous studies by Sondheimer and Hamilton (11) and Yahav et al. (12). In a similar way, Sondheimer and Hamilton found mild abnormalities in intestinal absorption that, in contrast to our results, could not be related to the type or severity of the cardiac lesion. Yahav et al. found minor absorptive abnormalities such as mild steatorrhea, bile salt loss, delayed gastric emptying, and abnormal triglyceride loading tests in their pa-

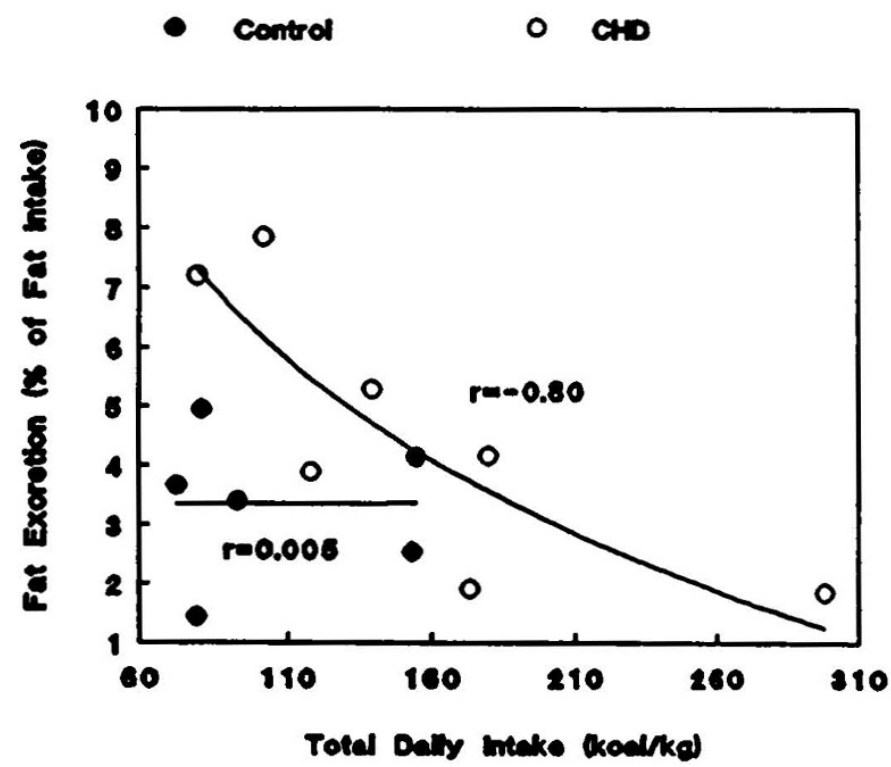

Figure 2. Fat excretion as a percentage of fat intake $v s$ total daily intake. tients but also concluded that intestinal malabsorption does not seem to cause failure to gain weight in these patients. Intestinal losses were not significantly increased in our patients, similar to the findings of Sondheimer and Hamilton (11) and Iber et al. (13).

Very few studies have measured water content in patients with $\mathrm{CHD}$ and congestive heart failure. Mellits and Cheek (14) measured TBW and ECW in older patients with CHD. In their younger group of patients, less than $137 \mathrm{~cm}$ in height, no difference was found between patients and normal controls. Brans et al. (15) determined body water content and distribution in 16 children aged $2 \mathrm{wk}$ to 28 mo before and after open-heart surgery for correction of CHD. TBW measured by antipyrine space and ECW as measured by the corrected bromide space were increased compared with values in normal controls. In malnourished patients with kwashiorkor, TBW and ECW as a percentage of body weight were increased, whereas the intracellular water compartment was contracted (16). Although they were receiving regular diuretics, some of our patients had increased TBW up to $120 \%$ of predicted.

Increased caloric intake was proved to increase body weight in patients with CHD and failure to thrive (17). On the other hand, different studies have shown contradictory results on the role of low caloric intake as a contributor to failure to thrive in patients with CHD. In a longitudinal study over a 6-mo period, Salzer et al. (18) followed 21 infants with CHD with and without cyanotic heart and a control group of patients with innocent cardiac murmur (18). Weight, length, and combined skinfold thickness were significantly lower in the two groups with CHD compared with the control group from 183 through $365 \mathrm{~d}$ of age. However, energy and protein intakes were similar in the two groups. It was concluded that a low level of food intake is not the main cause of inadequate growth and inadequate subcutaneous fat stores in infants with CDH. Strangway et al. (19) studied the relationship between diet and growth in 568 patients with CHD under $11 \mathrm{y}$ of age. They also concluded that nutrient intake is not an important factor limiting their growth. Other studies, on the other hand, found that growth failure appears to be most appropriately related to inadequate caloric intake rather than to other factors studied $(20,21)$. Some recent studies have shown that increased food energy content, up to $150-160 \mathrm{kcal} / \mathrm{kg}$ body weight $/ \mathrm{d}$, is associated with increments in length, weight, and subcutaneous tissue mass (22). Meeting such high needs may be a problem in unstable sick infants, who tend to be anorectic and may increase cardiac and respiratory rate during feeding (23). It was therefore suggested that feedings should be administered to these patients continuously over $24 \mathrm{~h}$ by nasogastric tube $(21,24)$. The increase in energy content of feedings needed to maintain weight gain in these patients is most probably not caused by decreased absorption or enteral loss but rather by increased energy expenditure. The studies that addressed this question showed increased oxygen consumption, indicating increased energy expenditure $(25,26)$. 
To study the interrelationships between the three parameters excess body water, energy intake, and energy absorption, a partial correlation analysis was used. A significantly positive association was found between excess water and malabsorption, whereas the correlation between energy intake and malabsorption was nonsignificant. The overall correlations between the different parameters indicate that excess body water content (TBW and ECW) is accompanied by increased energy and fat excretion. This relationship persists, even after accounting for the effect of energy intake on each of the parameters. Indeed, when considering the partial correlations, the association between energy intake and malabsorption seems to be explained by the effect of differences in TBW. Increased TBW and ECW by themselves do not ultimately indicate that our patients were congested due to relative heart failure. Undernutrition, as indicated by reduced weight as a percentage of ideal weight for height, is also accompanied by increased ECW (27). Unfortunately, the only way to evaluate lean body mass in this age group, less than $1 \mathrm{y}$, is by measuring TBW. Because we assume that our patients suffer from changes in their water compartments, this way of evaluation is not valid for this group. Furthermore, the shift of water in patients receiving daily diuretics is not known, and we therefore chose to express our results in relation to their TBW. We also believe that the lack of correlation between ECW and malabsorption is due to this fact. Nevertheless, ECW double that predicted and lack of correlation between weight as a percentage of ideal weight for height and fat and caloric malabsorption are less supportive of this possibility, and a more feasible hypothesis is that malabsorption is the result of relative congestion due to insufficient diuretics.

To prove a causative relationship between congestion due to heart failure and malabsorption, one should study patients with different degrees of congestion. Such a study would be unethical and very difficult to carry out because of an unstable clinical situation and changes in water compartments during the study due to diuretic treatment. Our patients were all receiving regular diuretics, which minimized the difference between them and other patients with CHD without a congestive component.

Low levels of energy intake were accompanied by increased levels of TBW. We believe that patients with excess body water are most probably sicker and therefore consume less, but that increased water content by

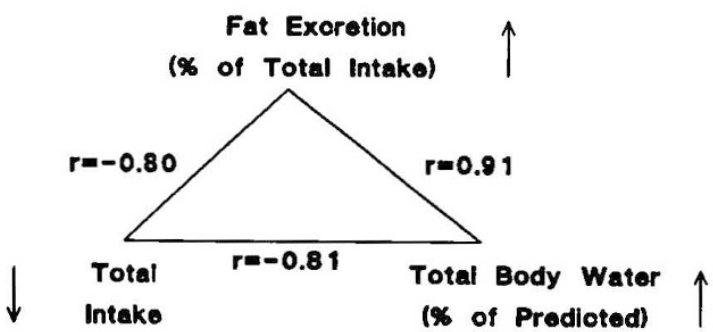

Figure 3. The relationship between caloric intake, excess body water content, and energy and fat excretion. itself, beyond the possible effect of intake, contributes positively to intestinal malabsorption. This relationship is best demonstrated in Figure 3.

Based on the above, we suggest that maintenance of water balance is essential for efficient absorption and can improve energy absorption for a given amount of energy intake. Our study indicates that infants with CHD receiving regular diuretics do not significantly malabsorb and will most probably gain weight if their TBW is not extremely expanded.

\section{REFERENCES}

1. Pittman JG, Cohen P 1964 The pathogenesis of cardiac cachexia. N Engl J Med 227:403-408

2. Gingell RL, Hornung MG 1989 Growth problems associated with congenital heart disease in infancy. In: Lebenthal E (ed) Textbook of Gastroenterology and Nutrition in Infancy, 2nd Ed. Raven Press, New York, pp 639-649

3. Rosenthal A 1993 Nutritional considerations in the prognosis and treatment of children with congenital heart disease. In: Suskind RM, Lewinter-Suskind L (eds) Textbook of Pediatric Nutrition. Raven Press, New York, pp 537-544

4. Moore DJ, Durie PR, Forstner GG, Pencharz PB 1985 The assessment of nutritional status in children. Nutr Res 5:424-425

5. Hill RE, Hercz A, Corey ML, Gilday DL, Hamilton JR 1981 Fecal clearance of $\alpha_{1}$ antitrypsin: a reliable measure of enteric protein loss in children. J Pediatr 99:416-418

6. Munro HN, Fleck A 1969 Analysis of tissue and body fluid for nitrogenous constituents. In: Munro HN (ed) Mammalian Protein Metabolism, Vol 3. Academic Press, New York, pp 424-525

7. Folch J, Lees M, Sloane Stanley GH 1957 A simple method for the isolation and purification of total lipids from animal tissues. J Biol Chem 226:497-500

8. Schoeller DA, Van Santen E, Peterson DW, Dietz W, Jaspen J, Klein D 1980 Total body measurements in human with ${ }^{18} \mathrm{O}$ and ${ }^{2} \mathrm{H}$ labeled water. Am J Clin Nutr 33:2686-2693

9. Vaisman N, Pencharz PB, Koren K, Johnson JK 1987 Comparison of oral and intravenous administration of sodium bromide for extracellular water measurements. Am J Clin Nutr 46:1-4

10. Cheek DB, Tabert JL 1968 Extracellular volume and body water in infants In: Cheek DB (eds) Human Growth. Lea \& Febiger, Philadelphia, pp 117-134

11. Sondheimer JM, Hamilton JR 1978 Intestinal function in infants with severe congenital heart disease. J Pediatr 92:572-578

12. Yahav J, Avigad S, Fraud M, Shem-Tov A, Barzilay Z, Linn S, Jonas A 1985 Assessment of intestinal and cardiorespiratory function in children with congenital heart disease on high caloric formulas. J Pediatr Gastroenterol Nutr 4:778-785

13. Iber FL, Cheek DB, Wolf KP 1967 Nitrogen metabolism in children with congenital cardiac defects and severe growth retardation. Am J Clin Nutr 20:1166-1170

14. Mellits ED, Cheek DB 1968 Growth and body water. In: Cheek DB (eds) Human Growth. Lea \& Febiger, Philadelphia, pp 135-149

15. Brans YW, Dweck HS, Harris HB, Parr GVS, Bailey PE, Kirklin JW, Cassady G 1981 Effect of open-heart surgery on the body composition of infants and young children. Pediatr Res 5:1024-1028

16. Brinkman GL, Bowie MD, Friis-Hansen B, Hansen JDL 1965 Body water composition in Kwashiorkor before and after loss of edema. Pediatrics 36:94 103

17. Jackson M, Poskitt EME 1991 The effects of high energy feeding on energy balance and growth in infants with congenital heart disease and failure to thrive. Br J Nutr 65:131-143

18. Salzer HR, Haschke F, Winger M, Heil M, Schilling R 1980 Growth and nutritional intake of infants with congenital heart disease. Pediatr Cardiol 10:17-23

19. Strangway A, Fowler R, Cunnigham K, Hamilton JR 1976 Diet and growth in congenital heart disease. Pediatrics 57:75-86

20. Huse DM, Feldt RH, Nelson RA, Novak LP 1975 Infants with congenital heart disease. Am J Dis Child 129:65-69

21. Bougle D, Iselin M, Kahyat A, Duhamd JF 1986 Nutritional treatment of congenital heart disease. Arch Dis Child 61:799-801

22. Heymsfield SB, Smith JS, Redd S, Withworth RB 1981 Nutritional support in cardiac failure. Surg Clin North Am 61:635-652

23. Thommessen M, Heiberg A, Kase BF 1992 Feeding problems in children with congenital heart disease: the impact on energy intake and growth outcome. Eur J Clin Nutr 46:457-464

24. Schwarz SM, Gewitz MH, See CC, Berezin S, Glassman MS, Medow CM, Fish BC, Newman LJ 1990 Enteral nutrition in infants with congenital heart disease and growth failure. Pediatrics 86:373-386

25. Krauss AN, Auld PAM 1975 Metabolic rate of neonates with congenital heart disease. Arch Dis Child 50:539-541

26. Stocker FP, Wilkoff W, Miettinen OS, Nadas AS 1972 Oxygen consumption in infants with heart disease. J Pediatr 80:43-51

27. Patrick J, Reeds PJ, Jackson AA, Seakins A, Picou DIM 1978 Total body water in malnutrition: the possible role of energy intake. Br J Nutr 39:417-424 